\title{
Effect of Design Parameters on the Internal Steam Reforming of Methane in Solid Oxide Fuel Cell Systems
}

\author{
Junjie Chen*, Xuhui Gao \\ Department of Energy and Power Engineering, School of Mechanical and Power Engineering, Henan Polytechnic University, Jiaozuo, China
}

Email address:

jietpj@163.com (Junjie Chen)

${ }^{*}$ Corresponding author

\section{To cite this article:}

Junjie Chen, Xuhui Gao. Effect of Design Parameters on the Internal Steam Reforming of Methane in Solid Oxide Fuel Cell Systems. American Journal of Modern Energy. Vol. 3, No. 3, 2017, pp. 38-49. doi: 10.11648/j.ajme.20170303.11

Received: May 10, 2017; Accepted: May 26, 2017; Published: June 30, 2017

\begin{abstract}
The operation of solid oxide fuel cell systems with the internal steam reforming of methane over supported nickel catalysts is studied. A mathematical model including heterogeneous chemistry, electro-chemistry, mass transport, and porous media transport is developed to explore the thermal energy coupling between the steam reforming and the electrochemical reactions, independent of the geometrical structure. The role of catalyst activity, inlet temperature, current density, and operating pressure in the system behavior is evaluated. A sensitivity analysis is also performed for different design parameters. The effect of flow configuration on the operation of the system is analyzed and compared based on multiple performance criteria. It is shown that the internal steam reforming within the fuel cell system can result in an overall auto-thermal operation which increases efficiency and simplifies the design process. However, a local cooling effect may occur close to the entrance of the reformer. The use of less active catalysts can cause the slippage of the methane. To reduce both the overall temperature increase across the fuel cell and the local cooling caused by the endothermic steam reforming reactions, increasing the operating pressure is found to be an effective approach. High system efficiency is obtained with increasing the operating pressure or decreasing the current density. The more efficient system is found for a co-flow configuration, while significant temperature gradients near the entrance of the reformer are not desirable for ceramic solid oxide fuel cell systems.
\end{abstract}

Keywords: Solid Oxide Fuel Cell, Steam Reforming, Design Parameter, Flow Configuration, Reaction Kinetics, Energy Conversion Efficiency

\section{Introduction}

Fuel cells are energy conversion systems that produce electricity directly from a gaseous fuel by electrochemical combination of the fuel with an oxidant. Fuel cells have many advantages compared to conventional electric power generation systems, such as environmental compatibility and high conversion efficiency [1]. Fuel cells have recently attracted increasing interest due to their potential for use in stationary and distributed electric power stations as well as in transportation applications [2]. At this stage, six types of fuel cells, i.e., the alkaline fuel cell (AFC), the phosphoric acid fuel cell (PAFC), the solid acid fuel cell (SAFC), the molten carbonate fuel cell (MCFC), the proton exchange membrane fuel cell (PEMFC), the direct methanol fuel cell (DMFC), and the solid oxide fuel cell (SOFC) have been mainly developed [3]. These fuel cells are characterized by the electrolyte used, which in turn determines the operating temperature [4].

Solid oxide fuel cells have recently emerged as a serious high temperature fuel cell technology. They promise to be extremely useful in large, high-power applications such as full-scale industrial stations and large-scale electricity-generating stations. Solid oxide fuel cells can also be used in motor vehicles [5]. A solid oxide fuel cell system usually utilizes a solid ceramic as the electrolyte and operates at extremely high temperatures. This high operating temperature allows internal reforming, promotes rapid electro-catalysis with non-precious metals, and produces high quality byproduct heat for co-generation. Efficiencies for this type of fuel cell can reach up to $70 \%$ with an additional $20 \%$ as heat recovery. Solid oxide fuel cells are best suited for provision of power in utility applications due to the significant time required to reach operating temperatures [6].

Solid oxide fuel cells have the promise to improve conversion efficiency, with a clean energy producing 
technology. These systems have exceptional potential for use as electric power generation systems due to their high energy conversion efficiency [7]. In addition, solid oxide fuel cells have many advantages such as long-term stability, simplicity of system design, and fuel flexibility. Furthermore, the exhaust heat can be used as a heat source for a variety of processes, with a relatively low cost. This together with the possibility of utilizing the remaining energy in a bottoming cycle for electric power generation causes a further increase in the overall energy conversion efficiency. The pressurized solid oxide fuel cell can be used to replace combustors in gas and steam turbines [8]. Such integrated solid oxide fuel cell-combustion turbine power systems are expected to reach very high energy conversion efficiencies. The high energy conversion efficiency will contribute to reduce or control carbon dioxide emissions. On the other hand, the largest disadvantage of these systems is the high operating temperature, causing longer start-up times as well as chemical and mechanical compatibility issues.

Most fuel cells require the conversion of the primary fuel into a hydrogen-rich gas. This can be achieved either directly in the fuel cell, causing higher overall energy conversion efficiency, or indirectly in fuel processing systems where the hydrocarbon feed is converted in an external catalytic steam reformer or a partial oxidation reactor [9]. The former approach is particularly relevant for solid oxide fuel cells, as these systems operate at very high temperatures to allow for the highly endothermic steam reforming reactions. Direct and indirect internal reforming solid oxide fuel cells are two possible approaches. In the former approach, methane is fed directly into the fuel cell and the steam reforming takes place directly on the anode [10]. In the latter approach, the reformer section is separate but adjacent to the anode of the fuel cell and in close thermal contact with it [11]. A potential problem within these systems is the mismatch between the thermal load associated with the rate of steam reforming reactions at typical operating temperatures of solid oxide fuel cells and the local amount of heat available from the reactions of solid oxide fuel cells [12]. This is caused by the inherent kinetics of the steam reforming reactions being extremely rapid relative to those of solid oxide fuel cells, due to the high nickel content. Under these conditions, significant local cooling can occur, causing thermally induced fractures of the ceramic components [13]. Therefore, within these systems, only a small fraction of the available steam reforming catalyst activity is required [14].

In this study, a steady-state model of an annular design of an indirect internal reforming solid oxide fuel cell is developed to explore the thermal energy coupling between the steam reforming and the electrochemical reactions. The effects of catalyst activity, fuel inlet temperature, current density, and operating pressure on the system behavior are studied. Comparisons with the co-flow configuration are also made. The objective of this study is to model a coupled steam reformer-solid oxide fuel cell system. Of special interest in this study is to explore how different catalyst activities, operating pressures, and flow configuration can affect the operation of solid oxide fuel cell systems.

\section{Modeling Approach}

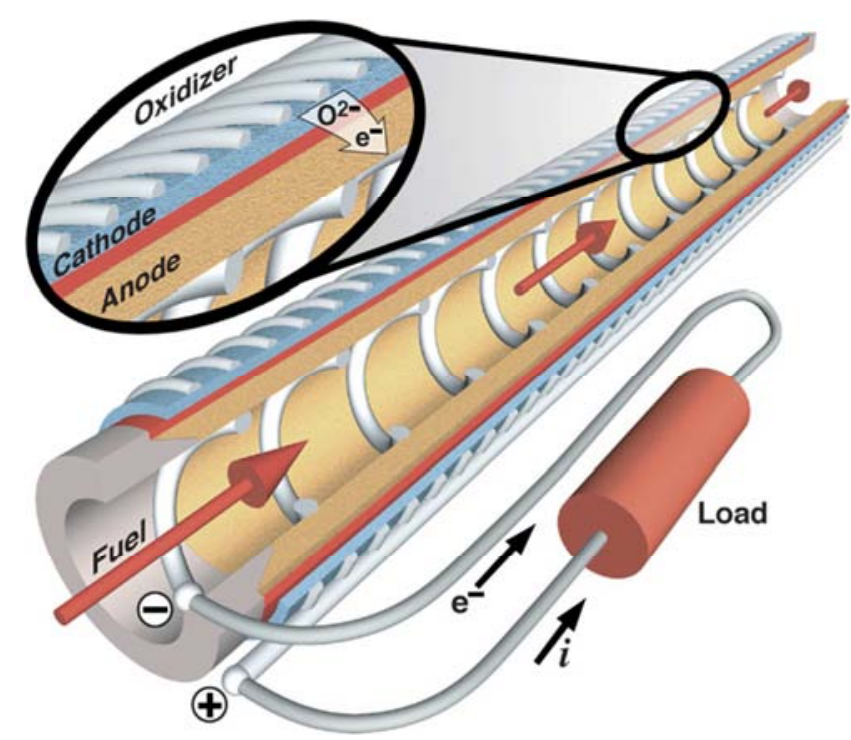

Figure 1. Nominal geometry for a tubular solid oxide fuel cell.

A solid oxide fuel cell essentially consists of two porous electrodes separated by a dense, oxygen ion conducting electrolyte. Solid oxide fuel cells in several different designs have been studied. These designs include planar and tubular geometries. The materials for fuel cell components in these different designs are either the same or very similar in nature. Figure 1 shows the nominal geometry for a tubular solid oxide fuel cell. In this design, the fuel cell components are deposited in the form of thin layers on a ceramic cathode tube. The materials for different fuel cell components have been selected based on the following criteria: (a) suitable electrical conducting properties required of different fuel cell components to perform their intended fuel cell functions; (b) adequate chemical and structural stability at high temperatures during fuel cell operation as well as during fuel cell fabrication; (c) minimal reactivity and inter-diffusion among different fuel cell components; (d) matching thermal expansion among different fuel cell components.

\subsection{Geometric Model}

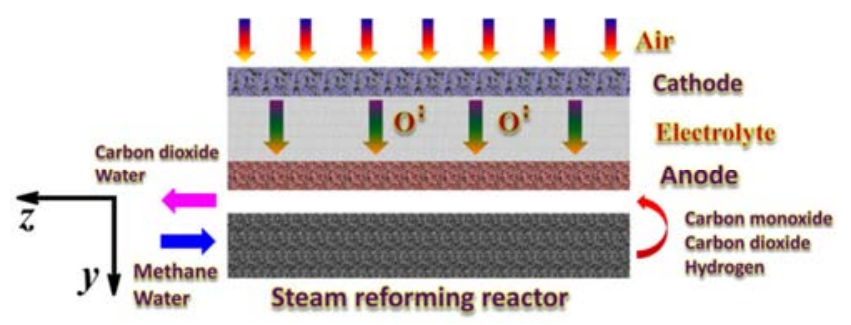

Figure 2. Schematic diagram of an indirect internal reforming solid oxide fuel cell.

Figure 2 shows the schematic diagram of an indirect internal reforming solid oxide fuel cell. The design of the planar fuel cell is the typical sandwich geometry employed in this study. The solid oxide fuel cell model presented here consists of two coupled chemical processes. A steam 
reforming reactor model is coupled with that of the solid oxide fuel cell. For the solid oxide fuel cell, several configurations are possible. The model studied here is based on a simple, generic annular design. In this design, the anode, electrolyte, and cathode layers are constructed around a tubular packed-bed steam reforming reactor. The fuel is first fed to the inner steam reform reactor in which the exit gases are then fed to the fuel cell anode. On the outer side, air is fed to the cathode of the solid oxide fuel cell. Counter-flow of fuel and air in the solid oxide fuel cell is employed in this study. This is denominated by a counter-flow configuration, despite the fact that a co-flow design is also feasible. This approach is a first step towards the development of reliable models for indirect internal steam reforming in more complex solid oxide fuel cell geometries. A supported nickel catalyst is considered in this study. The electrodes and electrolyte are ceramic materials. The major electrochemical reaction is the oxidation of fuel. A two-dimensional numerical model is developed, incorporated with heterogeneous chemistry, electro-chemistry, mass transport, and porous media transport.

\subsection{Channel Flow}

The two-dimensional thermal-fluid model is developed to study the coupled heat/mass transport and electrochemical reaction within the system. The quasi-two-dimensional counter-flow planar model solves for the gas channels by assuming plug flow [15]. The axial diffusion can be ignored, compared to the axial convective transport. The radial variation in species composition can be ignored, since the diffusive mixing is assumed to be predominant. The plug flow assumption is adequate to represent species transport within the system, since the channel dimensions considered in this study are quite small. Consequently, the model has no radial meshing, but a fixed number of cells/nodes in the axial direction. This obviously tends to affect the accuracy of the computed solution. The plug flow equation for species continuity in the channels can be written as

$$
\frac{\partial\left(\rho_{f} Y_{k}\right)}{\partial t}=-\frac{\partial\left(\rho_{f} v Y_{k}\right)}{\partial z}+\frac{P_{e}}{A_{c}} J_{k} W_{k}, k=1, \ldots, K_{g}
$$

The flow velocity in the channel can be computed from

$$
\frac{\partial\left(\rho_{f} v\right)}{\partial t}=-\frac{\partial\left(\rho_{f} v v\right)}{\partial z}+v \sum_{k=1}^{K_{g}} \frac{P_{e}}{A_{c}} J_{k} W_{k}
$$

In the above equations, $\rho_{f}$ is the fluid density, $Y_{k}$ is the mass fraction of species $k, t$ is the time, $v$ is the flow velocity, $z$ is the axial position, $P_{e}$ is the perimeter associated with the electrochemically active membrane electrode assembly (MEA), $A_{c}$ is the cross-sectional area of the channel, $J_{k}$ is the flux at the electrode channel interface, $W_{k}$ is the species molecular weight, and $K_{g}$ is the number of gas-phase species. A constant pressure is assumed within the system, and thus the density is computed from the ideal gas law and can be described by the following relationship:

$$
p=\frac{\rho_{f} R T}{\bar{W}} \text { and } \bar{W}=\sum_{k=1}^{K_{g}} X_{k} W_{k} .
$$

Here, $p$ is the pressure of the gas, $R$ is the ideal gas constant, $T$ is the absolute temperature of the gas, and $X_{k}$ is the mole fraction of species $k$. The flux at the electrode channel interface is computed using the dusty-gas model (DGM), which is a transport model describing the motion of fluid mixtures through porous media. These species molar fluxes depend on the local current density $i(z)$ and the heterogeneous chemistry within the porous-electrode structure. The one-dimensional electrochemical model does not solve for species transport in the gas channels.

\subsection{Porous Media Transport}

Since the electrode thickness is much smaller than its length, namely, due to geometrical considerations, the reaction-diffusion equation for species transport in the electrodes is solved one-dimensionally along its thickness, transverse to the direction of axial flow in the channel for the quasi-two-dimensional model in the counter-flow configuration. The one-dimensional electrochemical button cell model solves the governing equations along its discretized axisymmetric line. The transient form of the equation can be written as

$$
\frac{\partial\left(\phi \rho_{f} Y_{k}\right)}{\partial t}=-\frac{\partial\left(J_{k} W_{k}\right)}{\partial y}+\dot{s}_{k} W_{k} A_{s}, k=1, \ldots, K_{g}
$$

The total density of the fluid within the porous structure can be computed from

$$
\frac{\partial\left(\phi \rho_{f}\right)}{\partial t}=-\sum_{k=1}^{K_{g}} \frac{\partial\left(J_{k} W_{k}\right)}{\partial y}+\sum_{k=1}^{K_{g}} \dot{s}_{k} W_{k} A_{s}
$$

In the above equations, $\phi$ is the porosity, $\dot{s}_{k}$ is the heterogeneous molar production rate of the chemical species $k$, $y$ is the independent spatial variable along the thickness, and $A_{s}$ is the specific catalyst area available for surface reactions. The species molar flux $J_{k}$ in the porous bed is evaluated using the dusty-gas model equation as described below

$$
J_{k}=-\left[\sum_{l=1}^{K_{g}} D_{k l}^{D G M} \nabla\left[X_{l}\right]+\left(\sum_{l=1}^{K_{g}} \frac{D_{k l}^{D G M}\left[X_{l}\right]}{D_{l, K n}^{e}}\right) \frac{B_{g}}{\mu} \nabla p\right] .
$$

Here, $D_{k l}^{D G M}$ is the diffusion coefficients of the dusty-gas model, $[X]$ denotes the concentration of the gas, $D_{l, K n}^{e}$ is the effective binary diffusion, $B_{g}$ is the absolute permeability, and $\mu$ is the viscosity of the gas. The dusty-gas model is written as an implicit relationship between the molar fluxes, concentration gradients, pressure gradients, binary diffusion coefficients and Knudsen diffusion coefficients. It neglects the effect of thermo-diffusion and external forces. The porous medium is assumed to be a stationary component of the 
mixture where the Chapman-Enskog kinetic theory is used to estimate the binary diffusivities, while the pressure variations are proportional to the variations in gas concentrations. The equimolar counter diffusion assumption is no longer valid, since the flux ratios among gas species become complicated for multi-component systems. In this scenario, the dusty-gas model is recommended, over the Stefan-Maxwell model (SMM) or the Fick's model (FM) to represent porous media transport, to resolve flux ratios using Graham's law of diffusion in parallel with fluxes occurring due to electrochemistry [16]. This justifies the usage of the dusty-gas model, despite its computational expense. The first term on the right-hand side of the above equation represents the diffusive flux and the second term represents the viscous flux. $D_{k l}^{D G M}$ is defined as the diffusion coefficients of the dusty-gas model and is formulated as

$$
J D_{k l}^{D G M}=H^{-1}
$$

Here, the elements of the $H$ matrix can be written as

$$
h_{k l}=\left[\frac{1}{D_{k, K n}^{e}}+\sum_{j \neq k} \frac{X_{j}}{D_{k j}^{e}}\right] \delta_{k l}+\left(\delta_{k l}-1\right) \frac{X_{k}}{D_{k l}^{e}} .
$$

The permeability $B_{g}$ is given by the Kozeny-Carman equation:

$$
B_{g}=\frac{\phi^{3} d_{p}^{2}}{72 \tau(1-\phi)^{2}}
$$

In the above equations, $D_{k, K n}^{e}$ is the effective Knudsen diffusion coefficient of species $k, \delta$ is the Kronecker delta symbol, $d_{p}$ is the average diameter of particles, and $\tau$ is the tortuosity. The effective Knudsen diffusion $D_{k, K n}^{e}$ is obtained from the self-diffusion coefficient derived from the kinetic theory of gases:

$$
D_{k, K n}^{e}=\frac{\phi}{\tau} \frac{d_{\text {pore }}}{3} \sqrt{\frac{8 R T}{\pi W_{k}}}
$$

Here, $d_{\text {pore }}$ is the pore diameter. The effective Knudsen diffusion is highly dependent on the pore diameter, species molecular mass and temperature. The computed solution of the reaction-diffusion equation requires the boundary conditions at the electrode-electrolyte and electrode-gas chamber interfaces, as well as the reaction source terms $\dot{s}_{k}$. At the electrode-electrolyte interface, the chemical species fluxes are zero, while at the electrode-gas chamber interface, the inlet mass fractions serve as the boundary condition. The electrochemical reaction source terms enter as fluxes at the electrode-electrolyte interface.

\subsection{Electrochemistry}

A triple phase boundary (TPB) is the basically interfaces formed by the gas-phase, the electrolyte, and the electro-catalyst boundaries, and can be thought of as the active areas of the fuel cell. At this boundary, the charge transfer chemistry occurs. The electrochemical reactions that fuel cells use to produce electricity occur at the triple phase boundary. In this study, only the charge transfer occurring at the electrode-electrolyte interface, i.e., interfacial charge transfer, is taken into account, while the charge transfer across the utilization region of the electrodes, i.e., distributed charge transfer, is not taken into account. The net current density, with respect to electrochemically active species water/hydrogen and carbon dioxide/carbon monoxide, is computed as the normalized sum of currents $-i_{\mathrm{H} 2}$ and $i_{\mathrm{CO}}$ through two parallel pathways of charge transfer. Here, symbols with the subscript ' $\mathrm{H}_{2}$ ' correspond to the pathway involving water electrolysis, while those with the subscript ' $\mathrm{CO}$ ' correspond to the accompanying parallel pathway involving carbon dioxide electrolysis. The two analogous electro-chemical reactions normalize to a single value of current density through the charge and mass conservation equations. The potential balance equation in each pathway is formulated after taking into account all the irreversibility (resistances) that occurs during operation and is related to the current density by

$$
\begin{gathered}
E_{\text {cell }}=E_{\text {rev }, \mathrm{H}_{2}}+\left|\eta_{a}\left(i_{\mathrm{H}_{2}}\right)\right|+\eta_{c}\left(i_{\mathrm{H}_{2}}\right)+\eta_{\text {ohm }}\left(i_{\mathrm{H}_{2}}\right)+\eta_{\text {conc }}\left(i_{\mathrm{H}_{2}}\right) . \\
E_{\text {cell }}=E_{r e v, \mathrm{CO}}+\left|\eta_{a}\left(i_{\mathrm{CO}}\right)\right|+\eta_{c}\left(i_{\mathrm{CO}}\right)+\eta_{\text {ohm }}\left(i_{\mathrm{CO}}\right)+\eta_{\text {conc }}\left(i_{\mathrm{CO}}\right) .
\end{gathered}
$$

In the above equations, $E_{\text {cell }}$ is the cell potential, i.e., electromotive force (EMF), at the temperature of interest, $E_{\text {rev }}$ is the reversible potential between the electrode and the electrolyte, $\eta_{a}$ and $\eta_{c}$ are the activation over-potentials at the anode and cathode respectively, $\eta_{o h m}$ is the ohmic over-potential, and $\eta_{\text {conc }}$ is the concentration over-potential. The concentration over-potential is not treated explicitly as porous media transport is modeled in detail, i.e., the reversible potential is computed using gas-phase concentrations at the electrode-electrolyte interface. $E_{\text {rev }}$ is the reversible potential, which is the maximum possible potential that can be derived from a fuel cell operating reversibly and can be obtained from the Nernst equation:

$$
\begin{gathered}
E_{r e v, \mathrm{H}_{2}}=E_{\mathrm{H}_{2}}^{\Theta}+\frac{R T}{2 F} \ln \left(\frac{p_{\mathrm{H}_{2}, \mathrm{c}} p_{\mathrm{O}_{2}, \mathrm{a}}^{0.5}}{p_{\mathrm{H}_{2} \mathrm{O}, \mathrm{c}}}\right) . \\
E_{r e v, \mathrm{CO}}=E_{\mathrm{CO}}^{\Theta}+\frac{R T}{2 F} \ln \left(\frac{p_{\mathrm{CO}, \mathrm{c}} p_{\mathrm{O}_{2}, \mathrm{a}}^{0.5}}{p_{\mathrm{CO}_{2}, \mathrm{c}}}\right) .
\end{gathered}
$$

Here, $E^{\Theta}$ is the standard cell potential, i.e., the electromotive force at standard pressure, $p_{i}$ represents the partial pressures of hydrogen, water, carbon monoxide, carbon dioxide at the cathode triple phase boundary, as well as oxygen at the anode triple phase boundary. The temperature dependent $E^{0}$ is computed from thermodynamic data. The 
ohmic over-potential is given by

$$
\eta_{\text {ohm }}=R_{\text {tot }} i \text {. }
$$

Here, the total charge transfer resistance $R_{t o t}$ can be written as

$$
R_{\text {tot }}=R_{e}+R_{c}+R_{L S M}+R_{N i-Y S Z}
$$

The magnitudes of these resistances are highly dependent on the structure of the porous electrode as well as the type of material used [17]. In modern fuel cells, the contact resistances between solid-solid interfaces $R_{c}$ and the electronic resistances of both electrodes $R_{L S M}, R_{N i Y S S}$ can be ignored, compared to the ionic resistance of the electrolyte $R_{e}$, which is given by

$$
R_{e}=\frac{l_{e}}{\sigma_{e}}
$$

Here, $l_{e}$ is the thickness of the electrolyte, and $\sigma_{e}$ is the conductivity of an electrolyte solution, which varies as a strong function of the operating temperature as

$$
\sigma_{e}=\sigma_{0} T^{-1} \exp \left(\frac{-E_{e l}}{R T}\right)
$$

Here, $E_{e l}$ is the activation energy for ion transport and $\sigma_{0}$ is the pre-exponential factor [18]. The modified Butler-Volmer (B-V) equation is employed to describe the functional relationship between the activation losses and current density by considering the rate-limiting step among elementary charge transfer pathways. The electrochemical reduction of water is written as follows [19]:

$$
i_{\mathrm{H}_{2}}=i_{0, \mathrm{H}_{2}}\left[\exp \left(\frac{\left(1+\beta_{a}\right) F \eta_{c}}{R T}\right)-\exp \left(-\frac{\beta_{c} F \eta_{c}}{R T}\right)\right] .
$$

The modified Butler-Volmer equation, also known as Erdey-Grúz-Volmer equation, for the electrochemical reduction of carbon dioxide can be written as follows [20]:

$$
i_{\mathrm{CO}}=i_{0, \mathrm{CO}}\left[\exp \left(\frac{\beta_{a} F \eta_{c}}{R T}\right)-\exp \left(-\frac{\left(1+\beta_{c}\right) F \eta_{c}}{R T}\right)\right] .
$$

For the oxygen electrode, the Butler-Volmer equation for oxygen production can be described as follows [21]:

$$
i_{i}=i_{0, \mathrm{O}_{2}}\left[\exp \left(\frac{\beta_{a} F \eta_{a}}{R T}\right)-\exp \left(-\frac{\beta_{c} F \eta_{a}}{R T}\right)\right] .
$$

Here, $i$ denotes the electrode current density, $i_{0}$ is the exchange current density, $\beta$ is the asymmetric charge transfer coefficient, which is a dimensionless parameter and is considered to be the fraction of the change in polarization that causes a change in the reaction rate constant, $F$ is the Faraday constant, i.e., the number of coulombs per mole of electrons, and $\eta$ is the activation over-potential. The subscript index $i$ denotes either hydrogen or carbon monoxide, as the above equation involves two anode activation over-potentials for each charge transfer pathway, based on the type of electrolysis. The exchange current density is expressed as a function of temperature, and partial pressure of products and reactants participating in the charge transfer chemistry, although it makes more physical sense to express it as a function of the surface coverage of electrochemically active species and the open surface coverage. An Arrhenius expression is employed to describe the temperature dependence of exchange current density in the form of $i_{i}^{*}$, which can be written as

$$
i_{i}^{*}=k_{i} \exp \left(-\frac{E_{i}}{R T}\right) .
$$

Here, the subscript index $i$ refers to either oxygen, carbon dioxide, or water. A factor $\gamma$ is introduced to normalize the net current density and account for the relative percentages of water and carbon dioxide at the electrode-electrolyte interface, Due to the fact that the sites at the triple phase boundary are shared by both water and carbon dioxide. Therefore, the net current density is defined as follows:

$$
i=I_{\mathrm{H}_{2}}+I_{\mathrm{CO}}=\gamma i_{\mathrm{H}_{2}}+(1-\gamma) i_{\mathrm{CO}} \text { and } \gamma=\frac{Y_{\mathrm{H}_{2} \mathrm{O}}^{\mathrm{TPB}}}{\left(Y_{\mathrm{H}_{2} \mathrm{O}}^{\mathrm{TP}}+Y_{\mathrm{CO}_{2}}^{\mathrm{TPB}}\right)} \text {. }
$$

Here, $\gamma$ is the normalization factor for current density. This normalization factor approach has been proved and validated [22]. However, it is independent of certain factors affecting the triple phase boundary such as the fraction overlap between these particles, ratio of ionic to electronic particles, volume fraction of these constituents, foreign impurities in the triple phase boundary, co-ordination number of ionic and electronic particles, and degradation effects the over supported nickel catalysts.

\subsection{Thermo-Catalytic Chemistry}

For the $i$ th thermo-catalytic reaction in the cathode, a modified Arrhenius expression is employed to compute the forward reaction rate constant, based on the mean field theory. The forward reaction rate constant is expressed as follows:

$$
k_{f i}=A_{i}\left(\frac{T}{T^{0}}\right)^{\beta_{i}} \exp \left(-\frac{E_{a i}}{R T}\right)_{k=K_{g}+1}^{K_{g}+K_{s}} \theta_{k}^{\mu_{k i}} \exp \left(-\frac{\varepsilon_{k i} \theta_{k}}{R T}\right) .
$$

Here, $A_{i}$ is the pre-exponential factor, $E_{a i}$ is the activation energy, $\beta_{i}$ is the temperature exponent, $\theta_{k}$ is the surface coverage, $\mu_{k i}$ and $\varepsilon_{k i}$ are parameters modeling the order and activation energy dependency on the surface coverage for the $i$ th reaction, $K_{s}$ is the number of surface species. The temporal variations of surface coverage $\theta_{k}$ can be described as follows: 


$$
\frac{d \theta_{k}}{d t}=\frac{\dot{s}_{k} \sigma_{k}}{\Gamma}, k=K_{g}+1, \ldots, K_{g}+K_{s} .
$$

Here, $\sigma_{k}$ is the co-ordination number, i.e., the number of sites required for a species for adsorption, and $\Gamma$ is the density of the surface site. In this study, the density of the surface site is considered as $2.66 \times 10^{-9} \mathrm{~mol} \cdot \mathrm{cm}^{-2}$. In addition, $\dot{s}_{k}$ is the surface production rate of species $k$, which is expressed as follows:

$$
\dot{S}_{k}=\sum_{i=1}^{K_{r}} v_{k i} k_{f i} \prod_{k=1}^{K_{g}+K_{s}}\left[X_{k}\right]^{v_{k i}^{\prime}} .
$$

Here, $K_{r}$ is the number of surface reactions, $v_{k i}$ the difference in stoichiometric coefficients of products and reactants, $\left[X_{k}\right]$ denotes the concentration of species $k$, and $v_{k i}^{\prime}$ are the stoichiometric coefficients of the reactants. At steady state, the surface production rate is zero for the surface species, implying no variation in surface coverage with the time (although varying spatially).

While conventional methane steam reforming has been widely studied, there is only a small amount of data available for the kinetics of steam reforming in the anodes of solid oxide fuel cells. The detailed multi-step heterogeneous reaction mechanism proposed by Maier et al. [23] takes into account the adsorption/desorption of hydrogen, oxygen, methane, carbon monoxide, carbon dioxide and water from the surface of nickel-based catalysts. It also contains the methanation reactions, water-gas shift reaction, dry reforming, partial oxidation, steam reforming, formation of carbon monolayer, and total oxidation of methane. It has been made thermodynamically consistent in the development of surface reaction mechanisms, and is able to properly describe the steam reforming of methane over the supported nickel catalysts for a wide range of ratio of steam to methane and temperature [24]. Furthermore, the applicability of the heterogeneous reaction mechanism has been validated and tested with the experimental data obtained from the steam reforming of methane over nickel/alumina monoliths, and with additional data from the literature [25].

\subsection{Computational Scheme}

The governing equations vary based on the geometric configuration. The planar configuration solves the governing equations employed in the model, while the one-dimensional electrochemical button cell model solves the governing equations along its discretized axisymmetric line. In the former model, the porous media is resolved along its thickness for every axial node in the channel. However, the one-dimensional model does not solve for gas flow in the channels. Both the models solve for the reaction-diffusion equation along the discretized porous media, whose molar flux is computed using the dusty-gas model, with the provision of two boundary conditions. The first boundary condition at the electrode-gas chamber interface is given by the mass fractions in the gas channel. The second boundary condition equates to species fluxes that are computed based on the local current density at the electrode-electrolyte interface. Time integration of the one-dimensional electrochemical button cell model is performed, until steady state, to yield species mass fractions in the porous media. Consequently, at the electrode-electrolyte interface, the molar fluxes of the electrochemically active species can be specified as follows:

$$
J_{\mathrm{H}_{2} \mathrm{O}}=-J_{\mathrm{H}_{2}}=\frac{I_{\mathrm{H}_{2}}}{2 F}, J_{\mathrm{CO}_{2}}=-J_{\mathrm{CO}}=\frac{I_{\mathrm{CO}}}{2 F}, J_{\mathrm{O}_{2}}=-\frac{\left(I_{\mathrm{H}_{2}}+I_{\mathrm{CO}}\right)}{4 F} \text {. }
$$

A system of coupled non-linear equations can be treated as a differential-algebraic system mathematically, and can be solved using the finite-volume method. To solve these equations, they are first cast in finite-volume form. The cathode is discretized into 60 cells along its thickness and the anode is discretized into 18 cells. For the model, a marching algorithm is employed, beginning from the channel inlet and marching in $z$ toward the channel exit. Because of strong coupling and potentially stiff chemistry through the thickness of the membrane-electrode assembly in the $y$ direction, an implicit algorithm is used. The fluxes are defined at the cell faces, while all other properties are defined at the cell centers. The reaction rates are computed at constant fuel inlet temperature, since isothermal operating conditions are assumed. The equation system is solved using the differential algebraic equation (DAE) solver LIMEX [26]. In order to obtain the current density in each of the parallel electrochemical reaction pathways, a damped Newton iteration algorithm is employed to solve the system of algebraic model equations. The software is written in FORTRAN and is a part of the software package DETCHEM $^{\mathrm{TM}}[27]$.

\subsection{Model Validation}

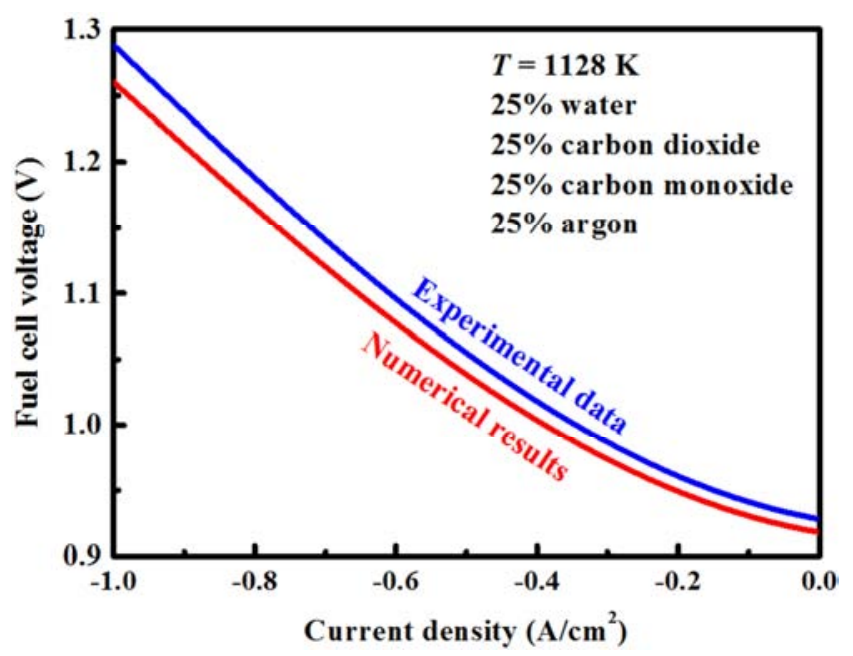

Figure 3. Effect of current density on the fuel cell voltage.

A set of experimental data is used to numerically validate the model. The fuel cell is composed of a NiO/YSZ porous support layer, $\mathrm{NiO} / \mathrm{YSZ}$ fuel electrode, $\mathrm{YSZ}$ electrolyte and LSM/YSZ oxygen electrode whose thicknesses are $300 \mu \mathrm{m}$, 
10-15 $\mu \mathrm{m}, 10-15 \mu \mathrm{m}$, and 15-20 $\mu \mathrm{m}$, respectively. The inlet flow rate of pure oxygen to the LSM/YSZ electrode is 20 liters per hour for all experiments. Planar $\mathrm{Ni} / \mathrm{YSZ}$ supported solid-oxide fuel cells of $5 \times 5 \mathrm{~cm}^{2}$, with an active electrode area of $4 \times 4 \mathrm{~cm}^{2}$, are used in the experiments. The $\mathrm{NiO}$ in the $\mathrm{Ni} / \mathrm{YSZ}$ electrode is reduced to nickel with hydrogen at 1288 $\mathrm{K}$, at start-up. The ceramic cell housing is used for fuel cell performance testing. The current collection is achieved using a nickel-grid and nickel-foam at the fuel electrode, while a platinum-grid is used at the air electrode. Gas inlets and outlets are symmetrical. As a result, the electrochemically active membrane electrode assembly may be tested in both co-flow and counter-flow configurations. It should be noted that the model validation is performed using experimental data that are obtained with the former configuration. The sealing of the fuel chamber relies on the smooth surfaces of the electrolyte layer and adjacent alumina frames. The air chamber is not sealed, but is always swept with $500 \mathrm{sccm}$ (standard-state cubic centimeter per minute) air. A thermocouple is inserted through a drilled hole in the anode frame, and is located at about $5 \mathrm{~mm}$ under the central point of the fuel cell. Therefore, the fuel cell temperature is obtained, which is usually different from the oven temperature. A bubbler humidifier is used to supply steam to the fuel cell. The polarization curves ( $i-V$ curves) are recorded by ramping the current through the cell at $5 \mathrm{~A}$ per minute from $i=0 \mathrm{~A}$. The fuel cell voltage is measured at $1128 \mathrm{~K}$ with an inlet gas composition of $25 \%$ water: $25 \%$ carbon dioxide: $25 \%$ carbon monoxide: $25 \%$ argon to the Ni/YSZ electrode. Computations are performed using the button cell model. A leakage over-potential is considered in each of the potential balance, and is formulated as

$$
\eta_{\text {leak }}=\eta_{\text {leak,max }}\left(1-\frac{i}{i_{\text {max }}}\right)
$$

Here, $i_{\max }$ is the maximum current density and a fit parameter. Additionally, $\eta_{\text {leak, } \max }=0.02 \mathrm{~V}$ and $i_{\max }=1.0 \mathrm{~A} / \mathrm{cm}^{2}$ are used. The computed values of area-specific resistance at $1.1 \mathrm{~V}$ are $0.287 \Omega / \mathrm{cm}^{2}$ at $1128 \mathrm{~K}$. The values of area-specific resistance correspond to the case where $\eta_{\text {leak,max }}=0.02 \mathrm{~V}$. Electrochemical input parameters are determined, through model validation, by making individual fits for varying compositions of water-hydrogen and carbon dioxide-carbon monoxide at $1128 \mathrm{~K}$. After calibration, the model is then validated for water-carbon dioxide-hydrogen-carbon monoxide mixtures. It is important to note that micro-structural properties are assumed to be within a realistic range due to their unavailability. Figure 3 shows the effect of current density on the fuel cell voltage. A good agreement between the numerical results and the experimental data is obtained.

\section{Results and Discussion}

The above two-dimensional numerical model is employed to simulate composition, temperature, and relevant electrochemical variables within the reformer and the solid oxide fuel cell, and their response to changes in the design parameters.

\subsection{Base Case}

To study the effect of the various design parameters, a base case needs to be defined. For this base case, the diameter of the steam reformer is $4.5 \mathrm{~mm}$, the total system diameter is 9.5 $\mathrm{mm}$, and the system length is $800 \mathrm{~mm}$. The inlet fuel is as follows: the ratio of methane to water is 0.5 , with small amounts of carbon monoxide and hydrogen and with the balance carbon dioxide. The operating pressure is $0.1 \mathrm{MPa}$ and the inlet temperatures of fuel and air are both $900^{\circ} \mathrm{C}$. The current density is assumed to be $3000 \mathrm{~A} \cdot \mathrm{m}^{-2}$, with an air ratio of 10.0 , and a fuel utilization of $75 \%$. These are typical design parameters for the operation of solid oxide fuel cells [28]. A reduced activity catalyst is employed in the reformer. Specifically, the relative activity of an indirect internal steam reforming catalyst is defined as the ratio between the activity of the catalyst that is currently in use and that of a conventional nickel catalyst at typical feed conditions, such as the composition, pressure, and temperature [29]. A reduced relative activity implies the use of either an inherently less active catalyst, a conventional catalyst with only a certain fraction of nickel content accessible, or a conventional nickel catalyst which is diluted. For the base case, the relative activity of catalysts is assumed to be $0.008 \%$. The developed model does not take steam reforming by carbon dioxide into account. Recent experimental studies have demonstrated that, at these compositions, carbon dioxide plays only a weak negative role in the rate of overall methane steam reforming reactions over supported rhodium catalysts in solid oxide fuel cells [30]. For the supported nickel catalyst considered in this study, it is assumed that the effect would be equally small and have been omitted from the model.

\subsection{Reaction Characteristics}

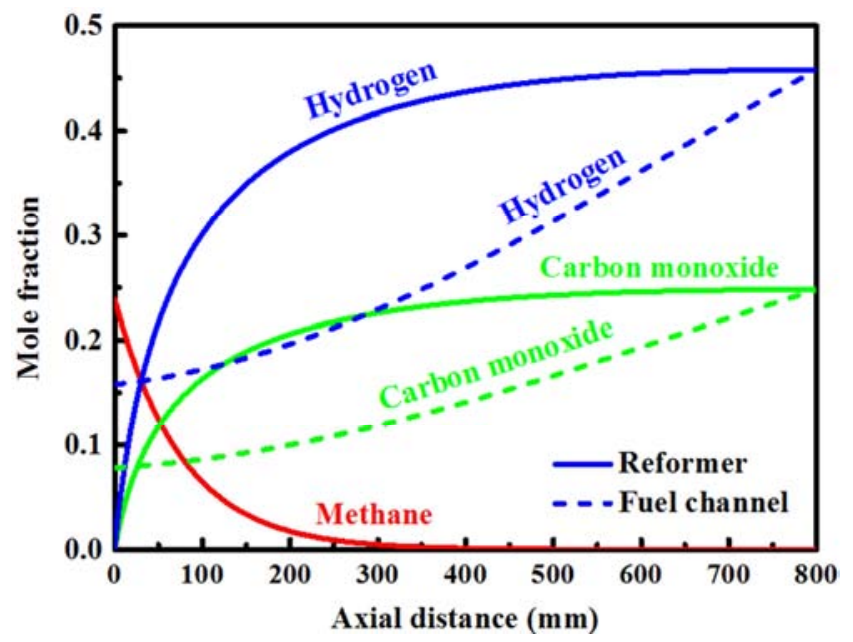

Figure 4. Methane, hydrogen, and carbon monoxide mole fraction profiles in the reformer and the fuel channel for the base case.

Figure 4 shows the methane, hydrogen, and carbon 
monoxide mole fraction profiles in the reformer and the fuel channel for the base case. A catalyst with a relative activity of $0.2 \%$ is employed. Complete methane conversion is achieved near the entrance of the reformer due to the very fast steam reforming reactions. Therefore, while the carbon monoxide and hydrogen mole fractions in this region increase rapidly, carbon dioxide, water, and methane mole fractions decrease. After this point, the reverse shift reaction results in a slight increase in carbon monoxide and water mole fractions and decrease in hydrogen and carbon dioxide mole fractions. At the outlet of the reformer, the stream content is $24.8 \%$ in carbon monoxide and $45.8 \%$ in hydrogen. This stream flows back into the solid oxide fuel cell in which the carbon monoxide and hydrogen are gradually converted to water and carbon dioxide, by means of the electrochemical reactions. In this case, there is a counter-flow configuration to the fuel stream in the reformer, and the terminal voltage is $0.688 \mathrm{~V}$ and the energy conversion efficiency of the system is $46.8 \%$. Furthermore, almost instantaneous fuel conversion would be achieved, if a supported catalyst with a higher amount of nickel is employed. However, the dilution is still within the regime of commercially available steam reforming catalysts, as a highly active supported catalyst with a high nickel content is employed.

\subsection{Effect of Catalyst Activity}

It has been found that the local cooling is caused by the fast steam reforming reactions. To eliminate this effect, it is necessary to slow down the rate of steam reforming reactions and the corresponding local energy flux demand. This could be achieved using catalysts sintered at high temperatures, partially poisoned catalysts, or catalysts with a much lower metal surface area. However, these methods are unlikely to guarantee long catalyst life. In the first method, sintering can easily result in complete pore blockage and thus unacceptable reduced overall rate of reaction, while the last two methods can result in high loss of catalyst activity whenever deactivation occurs either through sulfur poisoning or coke deposition [31]. In order to achieve such reduction in the rate of steam reforming reactions, it has been found that the use of a diffusive barrier placed near the outer surface of the catalyst and catalysts with non-uniform distribution of active metal within the inert support is an alternative and effective approach [32]. Additionally, this method tends to retain a low but approximately constant reaction rate, maintaining the performance of the catalyst, even in the face of possible deactivation. Furthermore, the use of oxide-based catalysts could be one other possible computed solution. Compared with conventional nickel steam reforming catalysts, such catalysts are highly resistant to carbon deposition and have a much lower catalytic activity [33].

Figure 5 shows the methane mole fraction and temperature profiles in the reformer for different catalyst relative activities. Here, the relative activities of $0.2 \%$ (base case), $0.04 \%$, and $0.008 \%$ are considered. The primary objective here is to understand what would happen if catalysts with such activities, which cover an activity range from metal to oxide-based catalysts, are used. As the activity of the catalyst is reduced, the temperature profile is definitely smoothed. For the lowest relative activity of catalysts, however, incomplete methane conversion is achieved in the reformer and flows through to the anode of the solid oxide fuel cell. In most cases, the model ignores the steam reforming reactions on the anode of the solid oxide fuel cell, since the methane concentration is very low. This determines a lower limit on the catalyst content allowed. However, the steam reforming reactions on the anode of the solid oxide fuel cell could be important when there is a significant carry-over of methane from the reformer of the system, if the kinetics on the anode of the solid oxide fuel cell are clear. The use of catalysts with non-uniform distribution of active metal within the inert support and an outer mass transfer barrier would also cause a smoother temperature profile with a slower but complete conversion of methane, which is similar to those presented for the $0.04 \%$ relative activity case [34]. Furthermore, these supported nickel catalysts can be optimized for the operating conditions of the system and desired final conversion with the advantage that their performance is not significantly affected by deactivation.

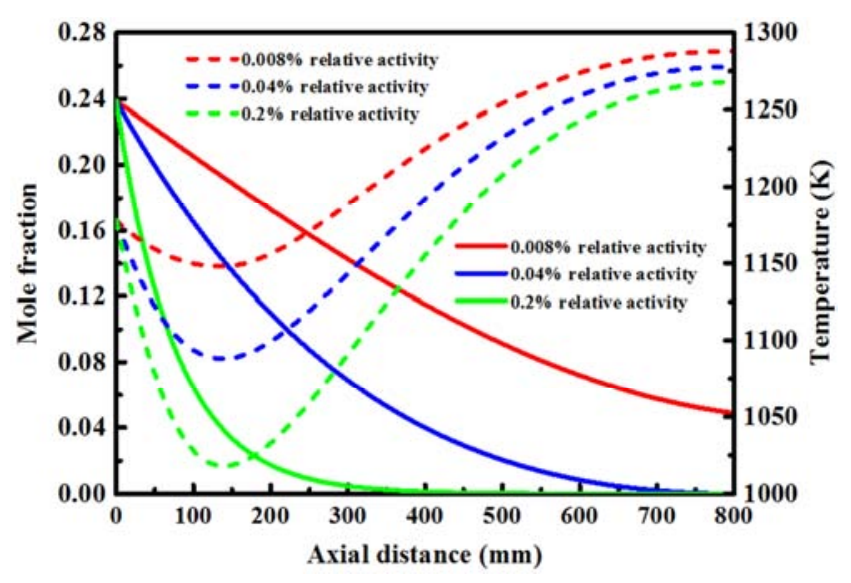

Figure 5. Methane mole fraction and temperature profiles in the reformer for different catalyst relative activities.

\subsection{Effect of Inlet Temperature}

In order to produce the hydrogen required by solid oxide fuel cells, the steam reforming of hydrocarbons over supported noble-metal catalysts is an attractive method. This process commonly occurs between $750^{\circ} \mathrm{C}$ and $900^{\circ} \mathrm{C}$ and is thus compatible with solid oxide fuel cells [35]. These operate at high enough temperature to allow for the endothermic steam reforming reactions, giving rise to an internal reforming solid oxide fuel cell. The heat released in a solid oxide fuel cell can provide the heat for the steam reforming reactions which can vary from $40 \%$ to $70 \%$ of the total amount of heat produced, depending on the operating conditions. Therefore, internal reforming solid oxide fuel cells eliminate the requirement for a separate fuel reforming process and are then expected to simplify the design of the overall system [36]. Additionally, while the requirement for fuel cell cooling is usually achieved by flowing excess air through the cathode, it can also be significantly reduced. One alternative to reduce the 
rate of steam reforming reactions at the entrance of the reformer could be reducing the fuel inlet temperature.

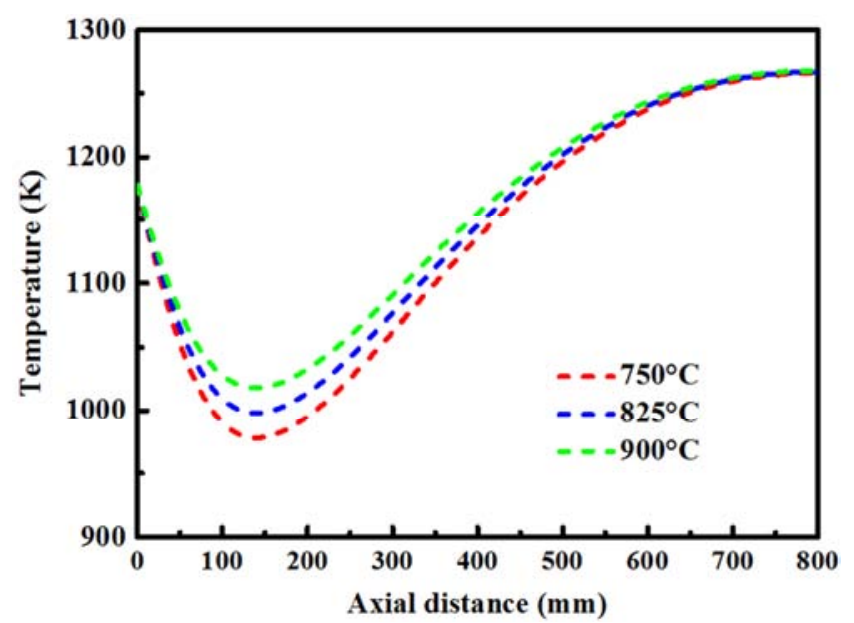

Figure 6. Temperature profiles in the reformer for different fuel inlet temperatures.

Figure 6 shows the temperature profiles in the reformer for different fuel inlet temperatures. Here, different fuel inlet temperatures of $750{ }^{\circ} \mathrm{C}, 825^{\circ} \mathrm{C}$, and $900^{\circ} \mathrm{C}$ (base case) are considered. As the fuel inlet temperature is reduced while maintaining the air inlet temperature, a smoother temperature profile at the entrance of the reformer is obtained, with an undesirable large temperature rise along the channel. Furthermore, it increases the over-potentials and thus decreases the potential and efficiency of the solid oxide fuel cell to $0.638 \mathrm{~V}$ and $45.8 \%$ for an inlet temperature of $750^{\circ} \mathrm{C}$ and to $0.646 \mathrm{~V}$ and $46.8 \%$ for an inlet temperature of $825^{\circ} \mathrm{C}$, respectively.

\subsection{Effect of Current Density}

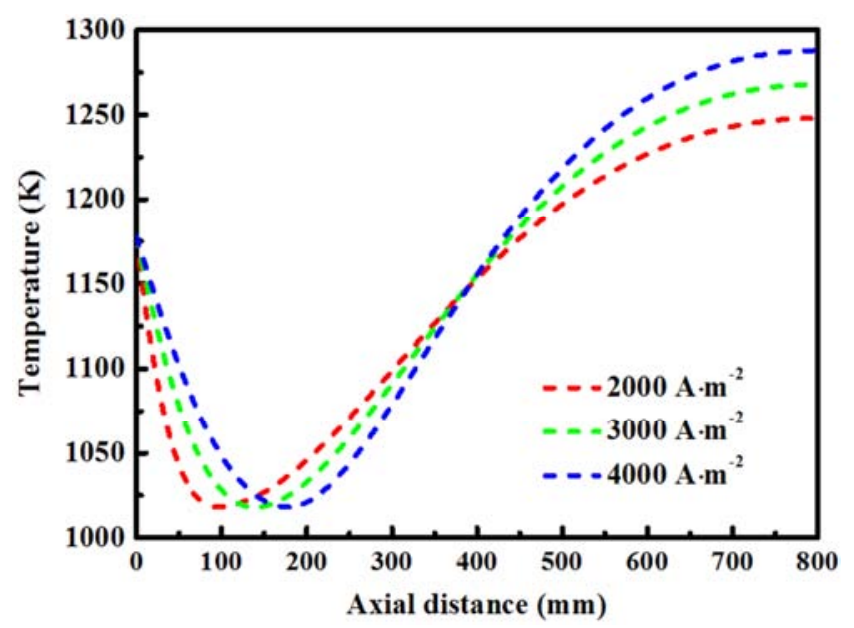

Figure 7. Temperature profiles in the reformer for different average current densities.

Figure 7 shows the temperature profiles in the reformer for different average current densities. Here, different average current densities of 2000, 3000 (base case), and $4000 \mathrm{~A} \cdot \mathrm{m}^{-2}$ are considered. An increase in the current density generates higher ohmic resistance and over-potentials, resulting in lower terminal voltages and lower efficiencies, $50.8 \%$ for a current density of $2000 \mathrm{~A} \cdot \mathrm{m}^{-2}$ against $40.8 \%$ for a current density of $4000 \mathrm{~A} \cdot \mathrm{m}^{-2}$, with a consequent increase in the outlet air temperature. As for the local cooling effect at the entrance of the reformer, there is no significant difference between the three selected current densities. In general, if the current density is to be increased, a higher air ratio is required to remove the excess heat produced within the system due to a less efficient operation. Within the system, there are no significant differences in the methane mole fraction profiles.

\subsection{Effect of Operating Pressure}

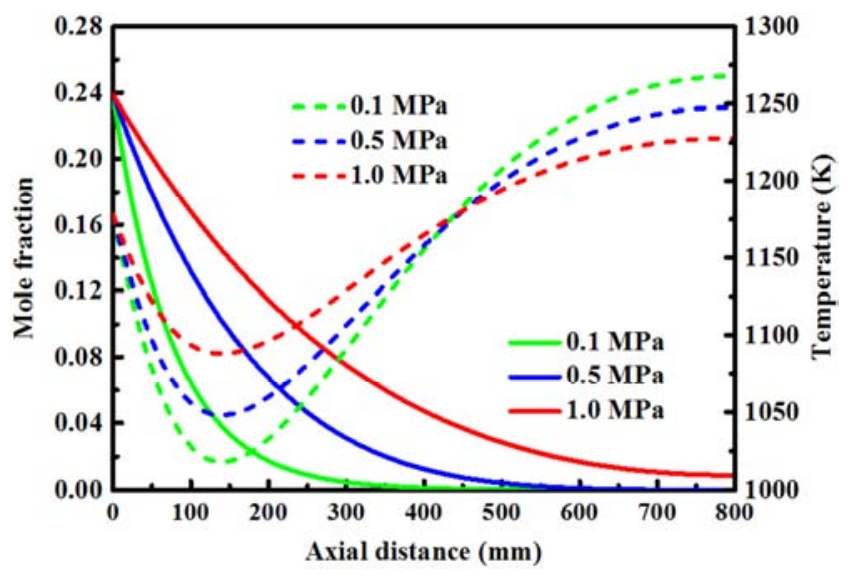

Figure 8. Methane mole fraction and temperature profiles in the reformer for different operating pressures.

Figure 8 shows the methane mole fraction and temperature profiles in the reformer for different operating pressures. Here, different operating pressures of 0.1 (base case), 0.5 , and 1.0 $\mathrm{MPa}$ are considered. The methane consumption rate decreases with increasing the operating pressure, reducing the local cooling effect at the entrance of the reformer. This is due both to the kinetic expressions that are currently in use and the thermodynamic restrictions, given the fact that the overall system temperature decrease, which further reduces the steam reforming reaction rate. On the other hand, higher open-circuit potential and lower over-potentials are obtained with the increase of operating pressure. This results in higher electric power, voltages, and to system efficiencies of $53.8 \%$ for an operating pressure of $0.5 \mathrm{MPa}$ and of $56.6 \%$ for an operating pressure of $1.0 \mathrm{MPa}$, and thus lower temperatures at the air/reformer outlet are achieved. Therefore, increasing the operating pressure is an effective way of reducing both the local cooling effect caused by the endothermic steam reforming reactions and the overall temperature increase across the solid oxide fuel cell.

\subsection{Effect of Flow Configuration}

As for the air flow, it first supplies heat to the steam reforming reactions and then removes the excess heat produced in the solid oxide fuel cell. It is possible to control to some extent the heat removal from the system and thus the temperatures at the inlet of the fuel channel or at the outlet of the air channel, by changing either the inlet temperature or the 
flow rate of this stream. So far a counter-flow configuration has been considered in this study. However, a co-flow configuration should also be analyzed to explore the system behavior. In order to understand how different flow configurations behave, the mass and energy balances in the air channel and corresponding boundary conditions are altered. The same operating conditions used for the above base case are considered.

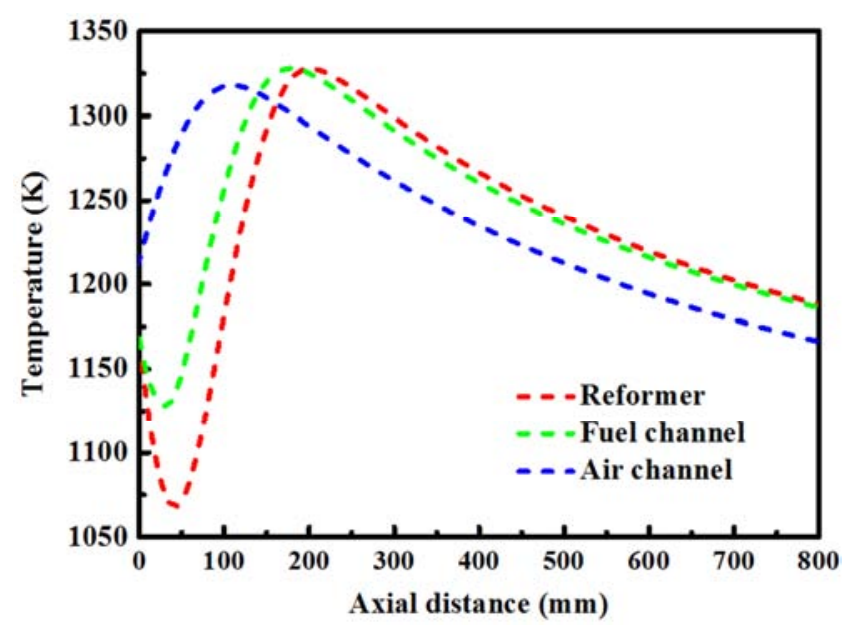

Figure 9. Temperature profiles in the reformer, fuel channel, and air channel for a co-flow configuration.

Figure 9 shows the temperature profiles in the reformer, fuel channel, and air channel for a co-flow configuration. While the counter-flow configuration increases the temperature along the air flow direction by heat accumulation with the maximum temperature at the outlet, the temperature profile in the co-flow configuration has a peak near the fuel/air outlet. Moreover, the temperature increase in the co-flow configuration is higher than that in the counter-flow configuration, since the air and fuel streams in the former configuration contain the generated heat without convecting it to the outside. The mean temperature within the system is higher, resulting in much lower over-potentials and consequent higher energy conversion efficiency. In the co-flow configuration, the terminal voltage is $0.698 \mathrm{~V}$ and the system efficiency is $50.8 \%$. The more efficient system has been found for a counter-flow configuration [37]. However, the system studied is direct internal reforming solid oxide fuel cells in a counter-flow configuration. In this case, the air has the highest temperature at the location where the heat of the steam reforming reactions is required. In the indirect internal reforming solid oxide fuel cell system studied here, this only occurs for a co-flow configuration. Therefore, the co-flow configuration is found to be the more efficient, by comparing both modes of operation. This is consistent with the behavior of co-flow configuration in indirect internal reforming solid oxide fuel cell systems [38]. However, the large temperature decrease observed near the entrance of the reformer is not desirable for a ceramic solid oxide fuel cell system. In terms of composition profiles, as the reformer temperature is higher, complete conversion of methane occurs earlier within the system.

\section{Conclusions}

A steady-state model of an indirect internal reforming solid oxide fuel cell has been developed to explore the thermal energy coupling between the steam reforming and the electrochemical reactions. The configuration is an annular design in which the solid oxide fuel cell is constructed around a tubular steam reforming reactor. The model combines heterogeneous chemistry, electro-chemistry, mass transport, and porous media transport. Simulations for different catalyst activities and operating conditions have been carried out. The main points can be summarized as follows:

(a) The use of typical metal-based steam reforming catalysts results in full methane conversion and undesirable local cooling at the entrance of the reformer. This local cooling is due to the mismatch between the thermal load associated with the rapid rate of steam reforming reactions and the local amount of heat available from the electrochemical reactions.

(b) Lower catalyst activities can smooth the temperature profiles, and can cause some methane slippage to the fuel channel of solid oxide fuel cells.

(c) As the fuel inlet temperature is decreases, a smoother temperature profile is obtained at the entrance of the reformer, with an undesirable temperature rise within the system.

(d) At lower current densities and higher operating pressures, higher system efficiency is achieved, with a consequent decrease in the overall system temperature rise across the solid oxide fuel cell. Additionally, higher operating pressures can reduce the local cooling effect at the entrance of the reformer, caused by the endothermic steam reforming reactions.

(e) For the counter-flow configuration, the temperature increases along the air flow direction with the maximum at the outlet, while for the co-flow configuration, the temperature profile has a peak near the fuel outlet. The co-flow configuration is found to be the more efficient system. However, significant temperature gradients are observed near the entrance of the reformer, which are not desirable for a ceramic solid oxide fuel cell system.

(f) As the catalyst activity decreases, incomplete methane conversion may be obtained within the reformer and subsequent the steam reforming of fuel would occur on the anode of solid oxide fuel cells. This is expected to result in a cooling effect at the entrance of the fuel channel.

\section{Acknowledgement}

This work was supported by the National Natural Science Foundation of China (No. 51506048).

\section{References}

[1] B. C. H. Steele and A. Heinzel. Materials for fuel-cell technologies. Nature, Volume 414, Issues 6861, 2001, Pages 345-352. 
[2] M. Winter and R. J. Brodd. What are batteries, fuel cells, and supercapacitors? Chemical Reviews, Volume 104, Issues 10, 2004, Pages 4245-4270.

[3] L. Carrette, K. A. Friedrich, and U. Stimming. Fuel cells Fundamentals and applications. Fuel Cells, Volume 1, Issue 1, 2001, Pages 5-39.

[4] A. Atkinson, S. Barnett, R. J. Gorte, J. T. S. Irvine, A. J. McEvoy, M. Mogensen, S. C. Singhal, and J. Vohs. Advanced anodes for high-temperature fuel cells. Nature Materials, Volume 3, Issues 1, 2004, Pages 17-27.

[5] O. Yamamoto. Solid oxide fuel cells: fundamental aspects and prospects. Electrochimica Acta, Volume 45, Issues 15-16, 2000, Pages 2423-2435.

[6] A. J. Jacobson. Materials for solid oxide fuel cells. Chemistry of Materials, Volume 22, Issues 3, 2010, Pages 660-674.

[7] E. D. Wachsman and K. T. Lee. Lowering the temperature of solid oxide fuel cells. Science, Volume 334, Issues 6058, 2011, Pages 935-939.

[8] A. Choudhury, H. Chandra, and A. Arora. Application of solid oxide fuel cell technology for power generation - A review. Renewable and Sustainable Energy Reviews, Volume 20, 2013, Pages 430-442.

[9] D. Mogensen, J.-D. Grunwaldt, P. V. Hendriksen, K. Dam-Johansen, and J. U. Nielsen. Internal steam reforming in solid oxide fuel cells: Status and opportunities of kinetic studies and their impact on modelling. Journal of Power Sources, Volume 196, Issue 1, 2011, Pages 25-38.

[10] V. Menon, A. Banerjee, J. Dailly, and O. Deutschmann. Numerical analysis of mass and heat transport in proton-conducting SOFCs with direct internal reforming. Applied Energy, Volume 149, 2015, Pages 161-175.

[11] S. H. Clarke, A. L. Dicks, K. Pointon, T. A. Smith, and A. Swann. Catalytic aspects of the steam reforming of hydrocarbons in internal reforming fuel cells. Catalysis Today, Volume 38, Issue 4, 1997, Pages 411-423.

[12] P. Aguiar, D. Chadwick, and L. Kershenbaum. Modelling of an indirect internal reforming solid oxide fuel cell. Chemical Engineering Science, Volume 57, Issue 10, 2002, Pages 1665-1677.

[13] P. Aguiar, D. Chadwick, and L. Kershenbaum. Effect of methane slippage on an indirect internal reforming solid oxide fuel cell. Chemical Engineering Science, Volume 59, Issue 1, 2004, Pages 87-97.

[14] J. R. Rostrup-Nielsen and L. J. Christiansen. Internal steam reforming in fuel cells and alkali poisoning. Applied Catalysis A: General, Volume 126, Issue 2, 1995, Pages 381-390.

[15] V. Menon, V. M. Janardhanan, S. Tischer, and O. Deutschmann. A novel approach to model the transient behavior of solid-oxide fuel cell stacks. Journal of Power Sources, Volume 214, 2012, Pages 227-238.

[16] R. Suwanwarangkul, E. Croiset, M. W. Fowler, P. L. Douglas, E. Entchev, and M. A. Douglas. Performance comparison of Fick's, dusty-gas and Stefan-Maxwell models to predict the concentration overpotential of a SOFC anode. Journal of Power Sources, Volume 122, Issue 1, 2003, Pages 9-18.

[17] V. Menon, Q. Fu, V. M. Janardhanan, and O. Deutschmann. A model-based understanding of solid-oxide electrolysis cells (SOECs) for syngas production by $\mathrm{H}_{2} \mathrm{O} / \mathrm{CO}_{2}$ co-electrolysis. Journal of Power Sources, Volume 274, 2015, Pages 768-781.

[18] H. Zhu and R. J. Kee. The influence of current collection on the performance of tubular anode-supported SOFC cells. Journal of Power Sources, Volume 169, Issue 2, 2007, Pages 315-326.

[19] H. Zhu, R. J. Kee, V. M. Janardhanan, O. Deutschmann, and D. G. Goodwin. Modeling elementary heterogeneous chemistry and electrochemistry in solid-oxide fuel cells. Journal of the Electrochemical Society, Volume 152, Issue 12, 2005, Pages A2427-A2440.

[20] G. Narasimhaiah and V. M. Janardhanan. Modeling $\mathrm{CO}_{2}$ electrolysis in solid oxide electrolysis cell. Journal of Solid State Electrochemistry, Volume 17, Issue 8, 2013, Pages 2361-2370.

[21] V. Menon, V. M. Janardhanan, and O. Deutschmann. A mathematical model to analyze solid oxide electrolyzer cells (SOECs) for hydrogen production. Chemical Engineering Science, Volume 110, 2014, Pages 83-93.

[22] V. Menon, V. M. Janardhanan, and O. Deutschmann. Modeling of solid-oxide electrolyser cells: From $\mathrm{H}_{2}, \mathrm{CO}$ electrolysis to co-electrolysis. ECS Transactions, Volume 57, Issue 1, 2013, Pages 3207-3216.

[23] L. Maier, B. Schädel, K. Herrera Delgado, S. Tischer, and O. Deutschmann. Steam reforming of methane over nickel: Development of a multi-step surface reaction mechanism. Topics in Catalysis, Volume 54, Issue 13, 2011, Pages 845-858.

[24] V. M. Janardhanan and O. Deutschmann. CFD analysis of a solid oxide fuel cell with internal reforming: Coupled interactions of transport, heterogeneous catalysis and electrochemical processes. Journal of Power Sources, Volume 162, Issue 2, 2006, Pages 1192-1202.

[25] V. M. Janardhanan and O. Deutschmann. Numerical study of mass and heat transport in solid-oxide fuel cells running on humidified methane. Chemical Engineering Science, Volume 62, Issues 18-20, 2007, Pages 5473-5486.

[26] P. Deuflhard, E. Hairer, and J. Zugck. One-step and extrapolation methods for differential-algebraic systems. Numerische Mathematik, Volume 51, Issue 5, 1987, Pages 501-516.

[27] O. Deutschmann, S. Tischer, C. Correa, D. Chatterjee, S. Kleditzsch, V. M. Janardhanan, N. Mladenov, H. D. Minh, H. Karadeniz, and M. Hettel. DETCHEM Software package, 2.5 ed., Karlsruhe, 2014, www.detchem.com.

[28] J. R. Ferguson, J. M. Fiard, and R. Herbin. Three-dimensional numerical simulation for various geometries of solid oxide fuel cells. Journal of Power Sources, Volume 58, Issue 2, 1996, Pages 109-122.

[29] J. Xu and G. F. Froment. Methane steam reforming, methanation and water-gas shift: I. intrinsic kinetics. AIChE Journal, Volume 35, Issue 1, 1989, Pages 88-96.

[30] P. Aguiar, E. Ramírez-Cabrera, N. Laosiripojana, A. Atkinson, L. S. Kershenbaum, and D. Chadwick. Oxide catalysts in indirect internal steam reforming of methane in SOFC. Studies in Surface Science and Catalysis, Volume 145, 2003, Pages 387-390. 
[31] K. Ahmed, L. Kershenbaum, and D. Chadwick. Sintering effects in a nickel-alumina catalyst. Chemical Engineering Science, Volume 44, Issue 4, 1989, Pages 999-1000.

[32] P. Aguiar, N. Lapeña-Rey, D. Chadwick, and L. Kershenbaum. Improving catalyst structures and reactor configurations for autothermal reaction systems: application to solid oxide fuel cells. Chemical Engineering Science, Volume 56, Issue 2, January 2001, Pages 651-658.

[33] E. Ramírez-Cabrera, A. Atkinson, and D. Chadwick. The influence of point defects on the resistance of ceria to carbon deposition in hydrocarbon catalysis. Solid State Ionics, Volumes 136-137, 2000, Pages 825-831.

[34] P. Aguiar, E. Ramírez-Cabrera, N. Lapeña-Rey, A. Atkinson, L. S. Kershenbaum, and D. Chadwick. Indirect internal steam reforming of methane in solid oxide fuel cells. Studies in Surface Science and Catalysis, Volume 136, 2001, Pages 501-506.
[35] S. A. Hajimolana, M. A. Hussain, W. M. A. Wan Daud, M. Soroush, A. Shamiri. Mathematical modeling of solid oxide fuel cells: A review. Renewable and Sustainable Energy Reviews, Volume 15, Issue 4, 2011, Pages 1893-1917.

[36] P. Aguiar, D. Chadwick, and L. Kershenbaum. Dynamic effects in autothermal systems: application to a coated-wall internally reformed solid oxide fuel cell. Chemical Engineering Research and Design, Volume 82, Issue 2, 2004, Pages 259-266.

[37] E. Achenbach. Three-dimensional and time-dependent simulation of a planar solid oxide fuel cell stack. Journal of Power Sources, Volume 49, Issues 1-3, 1994, Pages 333-348.

[38] L. Zhang, Y. Xing, H. Xu, H. Wang, J. Zhong, and J. Xuan. Comparative study of solid oxide fuel cell combined heat and power system with Multi-Stage Exhaust Chemical Energy Recycling: Modeling, experiment and optimization. Energy Conversion and Management, Volume 139, 2017, Pages 79-88. 